\title{
Risk factors for neurocognitive decline in lung cancer patients treated with prophylactic cranial irradiation
}

Citation for published version (APA):

Zeng, H., Hendriks, L. E. L., van Geffen, W. H., Witlox, W. J. A., Eekers, D. B. P., \& De Ruysscher, D. K. M. (2020). Risk factors for neurocognitive decline in lung cancer patients treated with prophylactic cranial irradiation: A systematic review. Cancer Treatment Reviews, 88, [102025].

https://doi.org/10.1016/j.ctrv.2020.102025

Document status and date:

Published: 01/08/2020

DOI:

10.1016/j.ctrv.2020.102025

Document Version:

Publisher's PDF, also known as Version of record

Document license:

Taverne

Please check the document version of this publication:

- A submitted manuscript is the version of the article upon submission and before peer-review. There can be important differences between the submitted version and the official published version of record.

People interested in the research are advised to contact the author for the final version of the publication, or visit the DOI to the publisher's website.

- The final author version and the galley proof are versions of the publication after peer review.

- The final published version features the final layout of the paper including the volume, issue and page numbers.

Link to publication

\footnotetext{
General rights rights.

- You may freely distribute the URL identifying the publication in the public portal. please follow below link for the End User Agreement:

www.umlib.nl/taverne-license

Take down policy

If you believe that this document breaches copyright please contact us at:

repository@maastrichtuniversity.nl

providing details and we will investigate your claim.
}

Copyright and moral rights for the publications made accessible in the public portal are retained by the authors and/or other copyright owners and it is a condition of accessing publications that users recognise and abide by the legal requirements associated with these

- Users may download and print one copy of any publication from the public portal for the purpose of private study or research.

- You may not further distribute the material or use it for any profit-making activity or commercial gain

If the publication is distributed under the terms of Article $25 \mathrm{fa}$ of the Dutch Copyright Act, indicated by the "Taverne" license above, 
Systematic or Meta-analysis Studies

\title{
Risk factors for neurocognitive decline in lung cancer patients treated with prophylactic cranial irradiation: A systematic review
}

\author{
Haiyan Zeng ${ }^{\mathrm{a}}$, Lizza E.L. Hendriks ${ }^{\mathrm{b}}$, Wouter H. van Geffen ${ }^{\mathrm{c}}$, Willem J.A. Witlox ${ }^{\mathrm{d}}$, \\ Danielle B.P. Eekers ${ }^{a}$, Dirk K.M. De Ruysscher ${ }^{a, *}$ \\ ${ }^{a}$ Department of Radiation Oncology (Maastro), GROW School for Oncology and Developmental Biology, Maastricht University Medical Center+, Maastricht, The \\ Netherlands \\ ${ }^{\mathrm{b}}$ Department of Pulmonary Diseases, GROW - School for Oncology and Developmental Biology, Maastricht University Medical Center +, Maastricht, the Netherlands \\ ${ }^{\mathrm{c}}$ Department of Respiratory Medicine, Medical Centre Leeuwarden, Leeuwarden, the Netherlands \\ ${ }^{\mathrm{d}}$ Department of Clinical Epidemiology and Medical Technology Assessment, GROW - School for Oncology and Developmental Biology, Maastricht University Medical \\ Center+, Maastricht, the Netherlands
}

\section{A R T I C L E I N F O}

\section{Keywords:}

Lung cancer

Prophylactic cranial irradiation

Neurocognitive decline

Cognition impairment

Risk factor

\begin{abstract}
A B S T R A C T
Background: Prophylactic cranial irradiation (PCI) reduces brain metastasis incidence in lung cancer, however with risk of neurocognitive decline. Nevertheless, risk factors for neurocognitive decline after PCI remain unclear.

Methods: We systematically reviewed the PubMed database according to the PRISMA guideline. Inclusion criteria were: randomized clinical trials (RCTs) and observational/single arm trials evaluating PCI, including $\geq 20$ patients, reporting neurocognitive test results for lung cancer. Primary aim: evaluate risk factors associated with neurocognitive decline after PCI.

Results: Twenty records were eligible ( 8 different RCTs, 8 observational studies), including 3553 patients in total (858 NSCLC, 2695 SCLC) of which 73.6\% received PCI. Incidence of mild/moderate cognitive decline after PCI varied from 8 to $89 \%$ (grading not always provided); for those without PCI, this was 3.4-42\%. Interestingly, 23-95\% had baseline cognitive impairment. Risk factors were often not reported. In one trial, both age ( $>60$ years) and higher PCI dose (36 Gy) including twice-daily PCI were associated with a higher risk of cognitive decline. In one trial, white matter abnormalities were more frequent in the concurrent or sandwiched PCI arm, but without significant neuropsychological differences. One trial identified hippocampal sparing PCI to limit the neurocognitive toxicities of PCI and another reported an association between hippocampal dose volume effects and memory decline. As neurocognition was a secondary endpoint in most RCTs, and was assessed by various instruments with often poor/moderate compliance, high-quality data is lacking.

Conclusions: Age, PCI dose, regimen and timing might be associated with cognitive impairment after PCI in lung cancer patients, but high-quality data is lacking. Future PCI trials should collect and evaluate possible risk factors systematically.
\end{abstract}

\section{Introduction}

Lung cancer patients frequently develop brain metastases (BM). For example, approximately $30 \%$ of radically treated stage III non-small cell lung cancer (NSCLC) patients present with symptomatic BM in the course of their disease, despite being treated with radical chemoradiotherapy [1]. In metastatic NSCLC with an oncogenic driver, BM incidence is up to $60 \%$ [2]. BM incidence of small cell lung cancer
(SCLC) patients is even higher (up to $80 \%$ at autopsy) [3]

$\mathrm{BM}$ are associated with a negative impact on quality of life (QoL) and survival [4-6]. Therefore, prevention of BM is necessary. In an individual patient data meta-analysis of patients with SCLC, prophylactic cranial irradiation (PCI) reduced the 3-year BM rate by $25.3 \%$ (58.6\% in the control versus $33.3 \%$ in the PCI arm, $\mathrm{P}<0.001$ ) and increased the 3-year overall survival (OS) rate by $5.4 \%$ (15.3\% in the control versus $20.7 \%$ in the PCI arm, $\mathrm{P}=0.01$ ). The majority had

* Corresponding author at: Department of Radiation Oncology (Maastro), GROW School for Oncology, Maastricht University Medical Center +, Dr Tanslaan 12, 6229 ET Maastricht, the Netherlands.

E-mail addresses: haiyan.zeng@maastro.nl (H. Zeng), lizza.hendriks@mumc.nl (L.E.L. Hendriks), wouter.van.geffen@znb.nl (W.H. van Geffen), willem.witlox@mumc.nl (W.J.A. Witlox), danielle.eekers@maastro.nl (D.B.P. Eekers), dirk.deruysscher@maastro.nl (D.K.M. De Ruysscher). 
limited disease SCLC [LD-SCLC]) with complete response on a simple chest X-ray after induction chemotherapy [7]. In extensive disease SCLC (ED-SCLC) patients responding to first line chemotherapy, the 1year BM rate was reduced by $25.8 \%$ (40.4\% in the control versus $14.6 \%$ in the PCI arm, P $<0.001$ ). The 1-year OS rate increased with $13.8 \%$ (13.3\% in the control versus $27.1 \%$ in the PCI arm, $\mathrm{P}=0.003$ ) [8]. Thus, PCI became standard of care in SCLC patients responding to initial therapy. However, a Japanese randomized controlled trial (RCT) showed that in ED-SCLC patients without BM on baseline magnetic resonance imaging (MRI), PCI followed by MRI follow-up did not result in a survival benefit compared with MRI follow-up alone (1-year OS $48.4 \%$ versus $53.6 \%$ for PCI versus observation, $\mathrm{P}=0.094$ ). PCI did reduce the $\mathrm{BM}$ rate by $26.1 \%$ at 1 -year $(59.0 \%$ in the control versus $32.9 \%$ in the PCI arm, P $<0.0001$ ) [9]. For NSCLC, PCI also significantly reduced the risk of BM development by $10.3-29.6 \%$, but this did not translate into an OS benefit, and therefore did not become standard of care in NSCLC [1,10-13].

As a downside, PCI increases short-term adverse events (mainly lowgrade toxicities such as headache, nausea, vomiting, fatigue, and alopecia). PCI is also associated with a long term and irreversible decline in neurocognitive functions, such as intellectual impairment, abnormalities on brain imaging, and in rare cases also dementia and ataxia $[1,6]$. Chronic neurocognitive decline has a negative impact on QoL and daily functioning $[14,15]$. According to the NVALT-11/DLCRG02 phase III RCT evaluating PCI versus observation in stage III NSCLC patients, total incidence of Common Terminology Criteria for Adverse Events (CTCAE) version 3.0 [16] grade 1-2 cognitive disturbance $(20.9 \%$ versus $3.4 \%)$ and memory impairment $(30.2 \%$ versus $8.0 \%)$ were significantly increased in the PCI arm [1]. However, no statistically significant nor clinically relevant impact of PCI on health-related QoL was observed (p-values, 0.641-0.914) [17].

Personalized treatment is important to avoid treatments that are not beneficial or even harmful for certain patients. Ideally, PCI is only administered to patients with a positive risk-benefit balance: i.e. preventing $\mathrm{BM}$ without a significant neurocognitive decline. For shared decision making, it is important to know the patients' personal risk factors for PCI associated cognitive decline. However, little is known about these risk factors. In 1994, Crossen et al proposed that the neurotoxicities of cranial irradiation might be related to age, radiation dose, fraction size, and timing of chemotherapy [18]. However, both imaging (i.e. the introduction of MRI for BM screening) and treatment modalities (i.e. more accurate radiation) have improved significantly the last 20 years and it is unclear whether the conclusions of Crossen et al are applicable to more recent literature. Furthermore, attention should be paid to potential confounding factors that might influence neurocognition such as anemia, depression and co-medication, and previous literature did not focus on these factors. Therefore, we performed a systematic review to evaluate potential risk factors for cognition decline after PCI in patients with lung cancer based on literature from 1995.

\section{Materials and methods}

\section{Study design}

This systematic review was conducted according to the PRISMA guideline (Preferred Reporting Items for Systematic reviews and MetaAnalyses) [19]. Before initiation we registered the protocol in the International prospective register of systematic reviews (PROSPERO 2020: Registered number: CRD42020155776)[79] .

\section{Main outcomes and measures}

The primary exposure was PCI, primary outcomes were cognitive functioning and risk factors associated with neurocognitive decline. Other outcomes (e.g. survival, BM incidence) were not reported as these have been reported extensively elsewhere $[6,20-26]$.

\section{Participants and search strategy}

The literature search was performed in the Pubmed database using the PICO method [27] (Table A.1) and included trials published from 01-jan-1995 to the search date (15-nov-2019). The full search terms are in Table A.2. The search was limited to full papers only, published in English. Eligibility criteria were: humans, lung cancer (SCLC/NSCLC), clinical trials containing cognitive function tests conducted at baseline and/or during follow up (with neurocognitive decline set as the primary endpoint or one of the secondary/exploratory endpoints), prospective phase II-IV trials (if two or more arms: randomized). The start date of 01-Jan-1995 was chosen for this review, as from 1995, brain MRI with gadolinium became more widely available (i.e. better exclusion of baseline BM). Exclusion criteria were: phase I trials, retrospective studies, reviews, duplicates, studies including $<20$ patients, studies including patients without pathological evidence of lung cancer, and studies in which neurocognitive outcomes were not reported. The detailed criteria are shown in Table A.3.

\section{Study selection and risk of bias assessment}

Two authors (HZ and WVG) independently selected papers for inclusion based on titles, abstracts, and full texts. A third author (LH) evaluated all papers with disagreement and consensus was sought through discussion.

A risk of bias assessment was done for the selected RCTs, using the Revised Cochrane risk-of-bias tool for randomized trials (RoB 2) $[28,29]$. Cognitive function was the outcome being assessed.

\section{Data extraction}

HZ extracted the following information from eligible full texts: title; first author; journal; publication year; recruitment period; study type; sample size (planned and actual enrollment); details of included patients (age, pathology, disease stage, smoking history, gender, comorbidities); MRI or CT of the brain before PCI and during follow-up; PCI details (fractionation schedule, initiation time); endpoints of the trial; type and timing of, and compliance to neurocognitive and QoL questionnaires; cognitive results and cognition conclusions. The results were checked by LH.

\section{Results}

\section{Study selection and characteristics}

The electronic literature search yielded 198 records after applying the preset filters (Human, English, publication date). Another five records were added through reference searching. Among these 203 records, 20 fulfilled the inclusion criteria (Fig. 1). Six were published between 1995 and 1998 [30-35], and 14 between 2007 and 2019 $[1,8,11,17,36-45]$. Twelve records were published out of eight different RCTs $[1,8,11,17,31,32,36,38,39,43-45]$ (NVALT-11 [1,17], RTOG 0214 $[11,44]$, Le Pechoux's trial $[38,39]$, Slotman's trial $[8,43]$ had two related publications), the other eight were observational studies [30,3335,37,40-42]). All the eligible observational trials were primarily designed to evaluate cognitive consequences of PCI, while most RCTs were primarily comparing OS or the BM incidence of PCI versus observation, or high dose PCI versus standard dose. Cognitive results were mostly included as secondary endpoints. The RTOG 0212 trial was the only RCT designed to evaluate cognitive consequences of PCI dose in LD-SCLC patients [45] (Table 1).

The eligible trials involved 3553 patients in total, including 858 (24.1\%) with NSCLC and 2695 (75.9\%) with SCLC, among whom 2616 (73.6\%) received PCI and the other 937 (26.4\%) did not. The median 

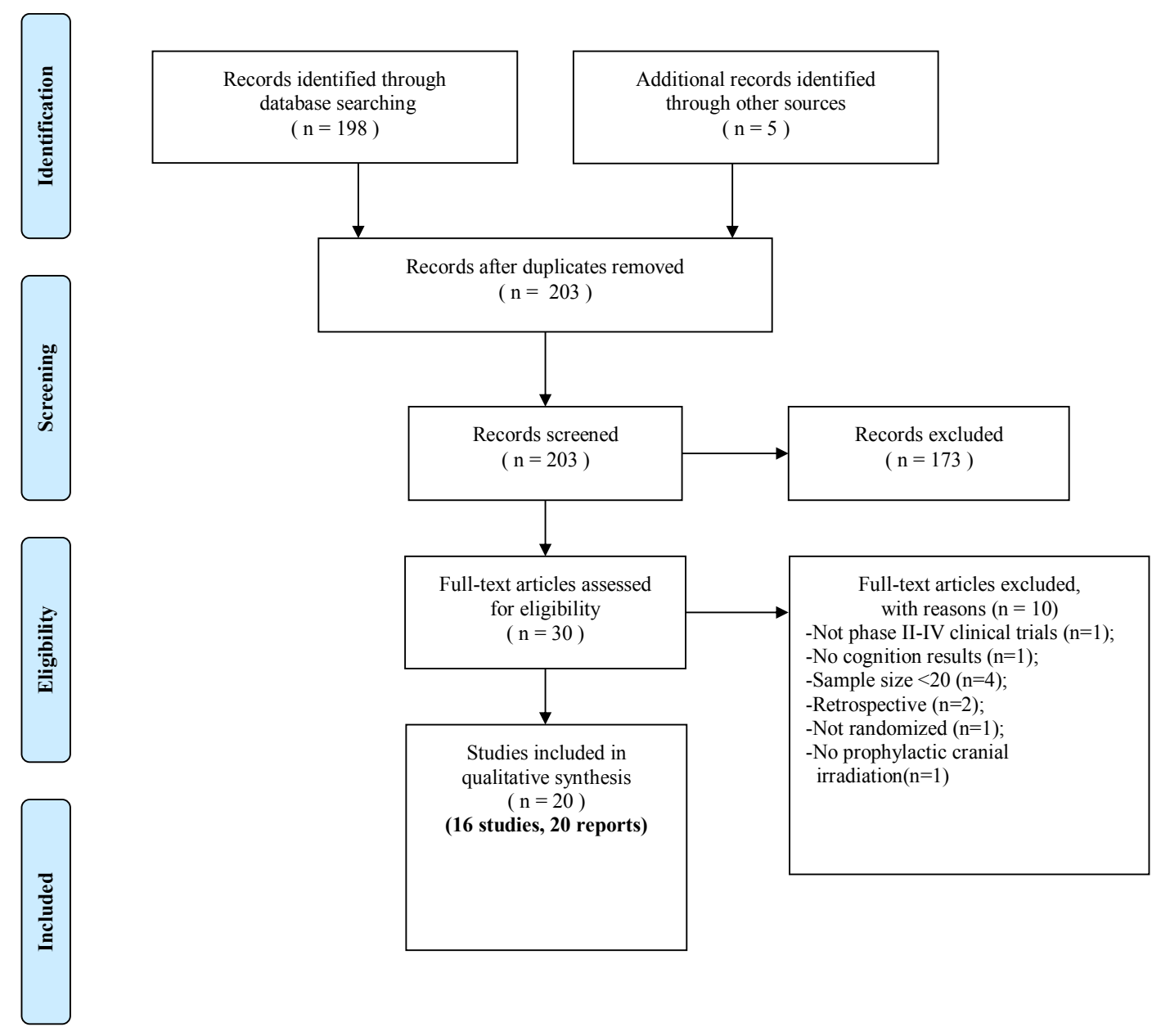

Fig. 1. PRISMA flow diagram.

age was approximately 60 years in all trials, and about $60 \%$ in most trials was male $[1,8,11,17,30,32,33,36-39,43-45]$. Only three trials reported smoking history $[17,41,42]$, three trials recorded comorbidities like hypertension and diabetes $[33,35,42]$, and seven trials did not report performance status $[32,34,35,38-41,45]$ (Table 2).

\section{Risk of bias assessment}

All observational trials were judged as high risk of bias, because of lack of a comparator arm. Six of the eight RCTs were assessed as high risk of bias $[1,8,11,17,31,36,43-45]$, the remaining two had "some concerns" [32,38,39]. None were assessed as low risk of bias (Fig. 2). This was mainly because cognitive function was secondary endpoint in most RCTs, while many data were missing because of poor assessment compliance (Fig. 2).

\section{Cognitive function tests and results}

The detailed cognition and QoL tests used are shown in Table 3. The most frequently used tests were the EORTC Quality-of-Life Questionnaire-C30 (QLQ-C30) (7 trials [1,8,11,17,38,39,41-45]), the EORTC QLQ Brain Cancer Module (BN20) (6 trials [1,8,11,17,38,39,41,4345]), Trail Making Test Part A (TMT-A) (6 trials [33,34,37,41,42,45]), Trail Making Test Part B (TMT-B) (7 trials [30,33,34,37,41,42,45]), Hopkins Verbal Learning Test (HVLT) (4 trials $[11,40,41,44,45]$ ), and Controlled Oral Word Association Test (COWAT) (4 trials $[33,37,41,45])$.

The definition of cognitive decline varied between trials. It was defined by comparing scores in seven trials $[8,30,33-35,37,42,43]$ or reliable change index (RCI) in five trials [11,36,40,41,44,45]. Other definitions are shown in Table A.4. Most RCTs noted a cognitive decline after PCI (incidence varied from 8 to $89 \%[1,32,38,39,44,45]$ ), but in some trials the effect was mild or moderate and did not result in a clinically significant decline. Some observational trials conducted in earlier years found that cognitive impairment was also found before PCI or before lung cancer treatment in general (Table 3, Table A.4).

Nine records showed that PCI leads to increased cognitive decline. In the pooled analysis of RTOG 0212 and 0214 , the odds ratio (OR) of PCI versus observation varied from 3.44 to 4.96 , all statistically significant [36]. In RTOG 0212, incidence of chronic neurotoxicity at 12 months after PCI varied from 60 to $89 \%$ in arms with different PCI doses [45]. In RTOG 0214, incidence of cognitive decline varied from 15 to $45 \%$ for PCI versus $5-17 \%$ for observation at different time points (3-12 months), all statistically significant [44]. In the NVALT-11, grade 1-2 cognitive disturbance (20.9\% in PCI versus $3.4 \%$ in observation) and memory impairment $(30.2 \%$ in PCI versus $8.0 \%$ in observation) were statistically significantly different $(\mathrm{P}<0.001)$ [1]. In Le Pechoux's trial, the incidence of cognitive decline after PCI varied from 34 to $47 \%$ at different time points (6-36 months) [38,39]. In Slotman's trial, according to the scores of the QoL tests, there was a maximum mean difference of 7.4 at week 6 for emotional functioning, 9.4 at week 6 for role functioning, and 8.8 at month 3 for cognitive functioning, all favoring the control arm $(\mathrm{P}>0.01)$ [43]. In Ahles' trial, there was a significant worsening in TMT-B (scores increased) after radiotherapy (including thoracic radiotherapy and PCI) (about 100 versus 130 in females and 120 versus 150 in males [extracted from figures], $\mathrm{P}<0.0001$ ) [30]. In Simó's longitudinal study, the cognitive functioning score dropped from $96.67 \pm 7.42$ at baseline to 


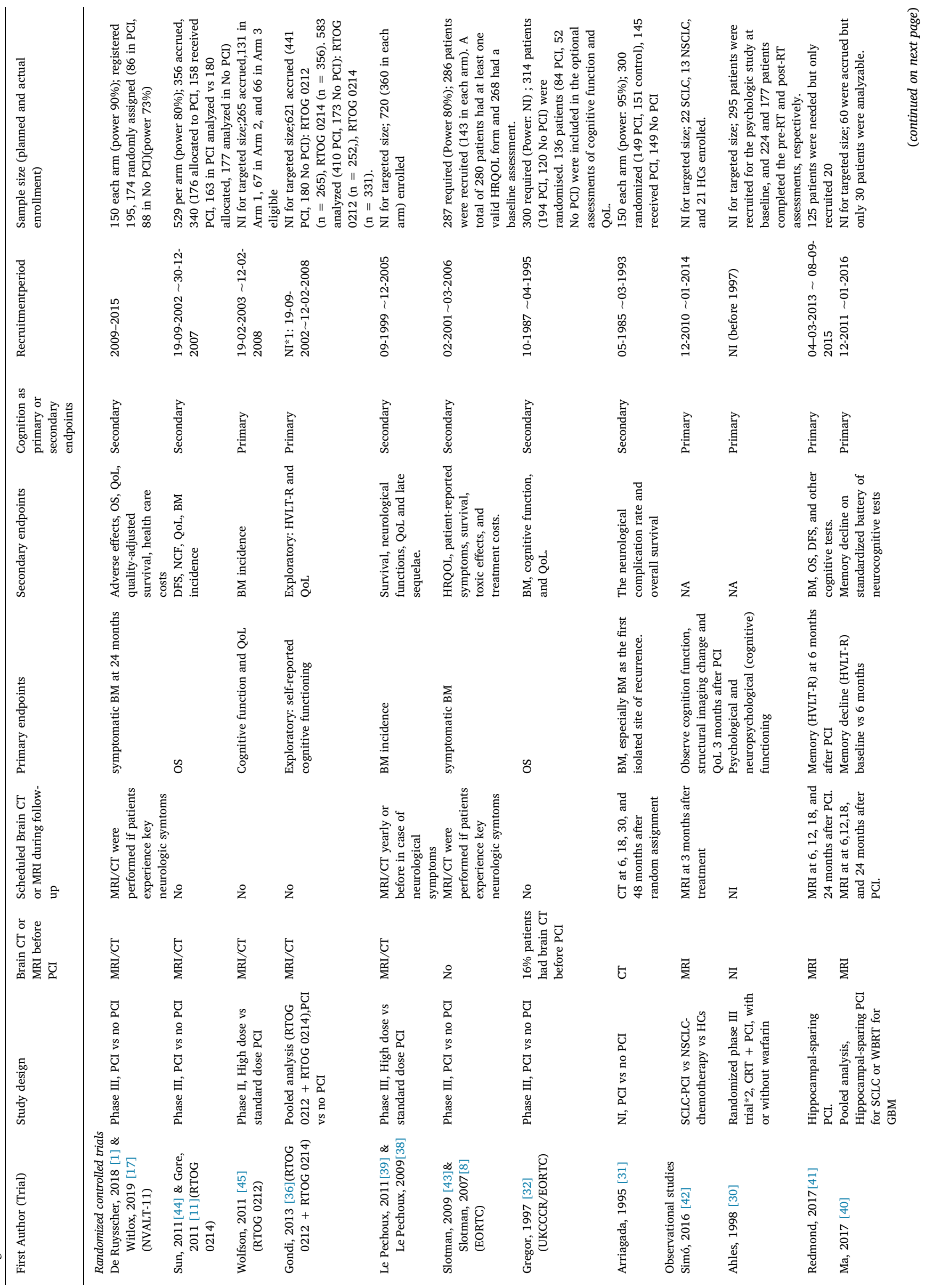


$89.17 \pm 15.57$ at 3 months after PCI $(\mathrm{P}=0.05)$ [42].

Five records observed no statistically significant increase of cognitive decline by PCI. In Slotman's trial, the impact of PCI was minor for cognitive functioning, only a difference of 8.8 at month 3 , which did not reach the 10-point clinically significant difference $(P=0.07)$ $[8,43]$. In the UKCCCR/EORTC trial, the incidence of impairment in patients without baseline impairment varied from 0 to $69 \%$ for PCI and $5-40 \%$ for observation in different tests at different time points (all $\mathrm{P}>0.05$ ) [32]. In the Arriagada's trial, the 2-year cumulative incidence of neuropsychological changes was not significantly different between PCI and observation (8-54\% versus 8-42\%, P-values $0.19-0.97)$ [31]. In Komaki's study, no significant differences between pre-PCI and post-PCI were noted on any of the tests (30.0-39.0 before PCI versus 28.3-38.4 after PCI, P-values 0.21-0.95) [33]. In Grosshans' study, for patients without progression, it was also not significantly different $(17.0 \pm 13.4$ before PCI versus $24.9 \pm 20.1$ after PCI, $\mathrm{P}=0.08)$ [37].

Five records reported that cognitive decline could already be detected before PCI. In Le Pechoux's trial, baseline cognitive decline was detected in $23-25 \%$ of patients [39]. In the UKCCCR/EORTC trial, 24-42\% had baseline cognitive impairment [32]. In Arriagada's trial, only 94 of 229 (41\%) assessed patients did not show abnormalities at the initial neuropsychological examination [31]. In Komaki's trial, 97\% ( 29 out of 30 ) of the patients had evidence of cognitive dysfunction before PCI and 20 out of 21 (95\%) patients with no prior neurologic or substance abuse history had impairments on cognitive assessment [33]. In Grosshans' trial, $47 \%$ displayed cognitive impairment prior to PCI [37].

Two studies found that cognitive decline existed in lung cancer. Van Oosterhout's two studies on SCLC showed clear differences between the pre-therapeutic performance of patients and that of matched controls ( $\mathrm{P}<0.001$ [34], $\mathrm{P}<0.006$ [35]).

\section{Risk factors for cognitive impairment after PCI}

Although all the eligible records reported whether PCI resulted in cognitive decline, risk factors for neurocognitive decline after PCI were mentioned in only a few trials (Table 4).

RTOG 0212 found that age ( $>60$ years) was a risk factor for developing cognitive impairment $(\mathrm{P}=0.005)$ in patients with LD-SCLC [45]. Le Pechoux's trial confirmed the importance of age (continuous) as a risk factor of neurocognitive decline (memory impairment: hazard ratio $[\mathrm{HR}]=1.04, \mathrm{P}=0.005$ ) [39]. The pooled analysis of RTOG 0212 and RTOG 0214 also indicated that age ( $>60$ years) was associated with higher rates of HVLT-delayed recall decline at 12 months (OR 2.52, 95\%CI 1.06-5.99, $\mathrm{P}=0.04$ ) [36].

In addition, RTOG 0212 also reported that patients with a high PCI dose (36 Gy) were more likely to develop cognitive decline compared to those with standard dose (25 Gy) PCI ( $\mathrm{P}=0.03$ ) [45]. However, Le Pechoux's trial showed that there were no statistically significant differences between the higher dose (36 Gy) and standard dose (25 Gy) PCI arms (all P-values > 0.02) [39]. Of note, the patients of the RTOG 0212 trial were included in Le Pechoux's trial. Another pooled analysis of RTOG 0212 and RTOG 0214 also demonstrated no difference between high- and low-dose PCI in terms of cognitive decline [36]. However, all these trials concluded that 25 Gy should still be the standard of care for PCI in SCLC since higher doses did neither reduce the incidence of $\mathrm{BM}$ nor improve OS compared with standard dose $[38,39,45]$. Possibly, twice-daily fractions for PCI also contributed to the increase in cognitive decline, because in RTOG 0212 the cognitive functioning in QLQ-C30 declined more obviously in the twice-daily PCI arm (mean change scores: -14.0 in 25 Gy arm, -13.5 in 36 Gy with once-daily 18 fractions arm, and-19.6 in 36 Gy with twice-daily 24 fractions $\mathrm{arm}$ ) and the incidence of BM was higher in the twice-daily arm (10\% in once-daily 18 fractions arm versus $21 \%$ in twice-daily 24 fractions arm) [45]. 


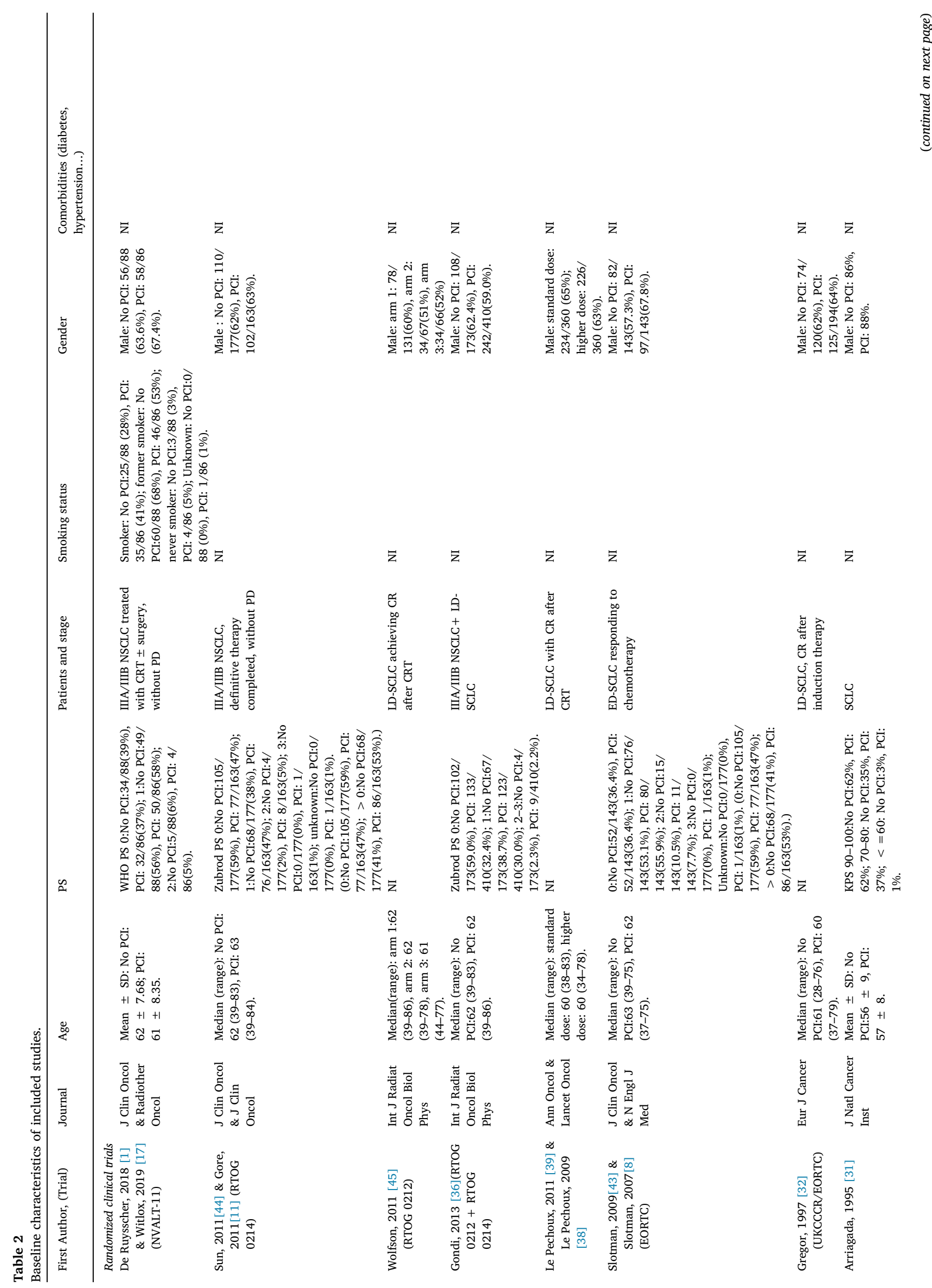




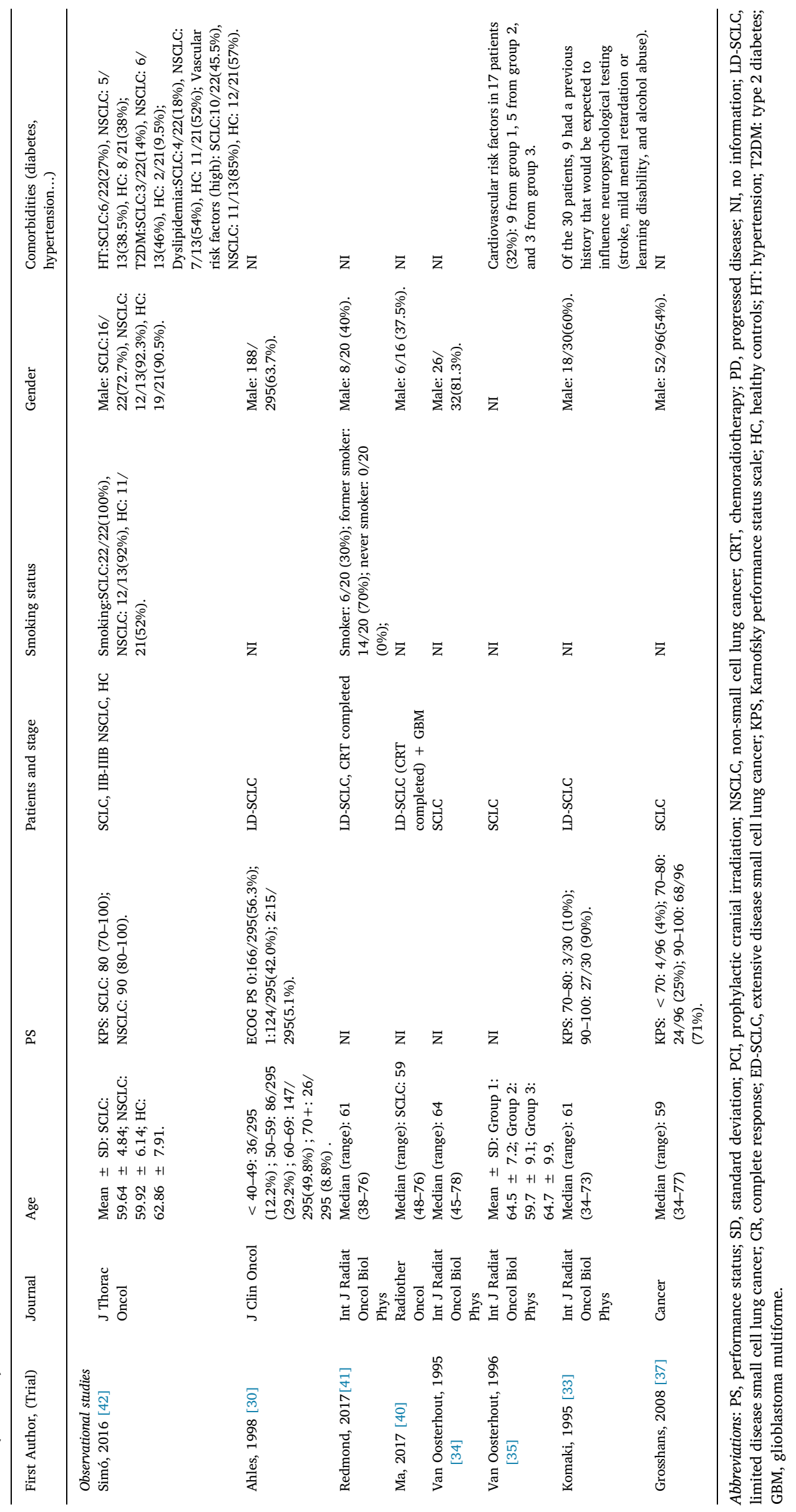




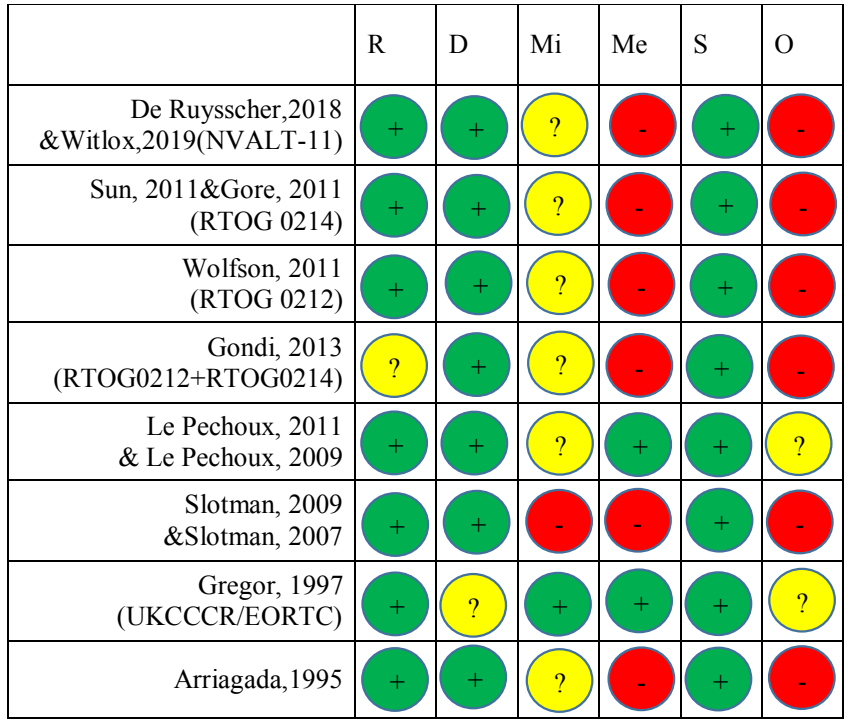

Fig. 2. Risk of bias assessments. Risk of bias legend. $\mathbf{R}$ Bias arising from the randomisation process. D Bias due to deviations from intended interventions. Mi Bias due to missing outcome data. Me Bias in measurement of the outcome. $\mathbf{S}$ Bias in selection of the reported results. O Overall risk of bias. Domain 1: Risk of bias arising from the randomization process: All trials were assessed as at low risk of bias except the pooled analysis of RTOG 0212 and RTOG 0214: this had "some concerns" because the educational level was unbalanced between arms $(P=0.02)$ [36]. Domain 2: Risk of bias due to deviations from the intended interventions (effect of assignment to intervention): the UKCCCR/EORTC trial is the only one that was assessed to have "some concerns" because the poor accrual during the first four years was mainly due to some radiotherapists not wishing to use the mandated PCI regimens [32]. The others were at low risk. Domain 3: Missing outcome data: all RCTs were hampered by the decreasing compliance of cognitive assessments throughout time, although with balance in both arms. Therefore, six trials were assessed to have some concerns. The Slotman's trial was judged to be at high risk of bias because data might not be missing at random (23.8\% forms were not filled in since the patient was or felt too ill to complete the questionnaire and the return rate of forms for patients with BM was lower than those without BM) $[8,43]$. The UKCCCR/EORTC trial was judged as at low risk since the missing data were balanced between arms and mainly due to logistical or protocol factors, rather than patients' deteriorating conditions [32]. Domain 4: Risk of bias in measurement of the outcome: Six trials were judged to be at high risk because the assessors were aware of the intervention received by study participants [1,43] or the assessment of the outcome probably could have been influenced by knowledge of whether PCI was received or not $[31,36,44,45]$. The UKCCCR/EORTC trial was judged to be at low risk of bias because centers performed evaluation blinded to PCI status [32]. The Le Pechoux's trial $[38,39]$ was at low risk of bias because they were comparing high dose vs standard dose instead of PCI or not, based on patientreported data. Domain 5: Risk of bias in selection of the reported result: All trials were assessed as at low risk of bias because they reported the cognitive results in accordance with a pre-specified analysis plan. Overall risk of bias: Only the Le Pechoux's trial $[38,39]$ and UKCCCR/EORTC trial [32] were judged to have some concerns. The other six trials were judged as high risk of bias. This is mainly because of domain 3 and domain 4 .

Van Oosterhout et al assessed whether treatment variables had an effect on cognitive functioning, but they found that there were no significant correlations between neurocognitive outcomes and number of chemotherapy courses, type of chemotherapy, total and fraction dose of PCI [35]. The only difference was that white matter abnormalities were more frequent in the arm of concurrent or sandwiched PCI (PCI between chemotherapies). Ahles's study [30] noticed that female patients performed worse in psychological tests, suggesting that female patients might be more distressed than male patients, and might need more psychological support. Two records evaluated hippocampus avoidance (HA) techniques to protect cognitive function (Redmond's trial [41] and Ma's pooled-analysis [40]) and indicated that there was a potential benefit of HA in limiting neuropsychological toxicities of brain radiation, with an association between hippocampal dose volume effects and memory decline.

\section{Cognitive assessment compliance}

Most trials were designed to assess cognitive functioning at baseline and to repeat this assessment at a series of time points during follow up. However, compliance dropped down rapidly from baseline to follow-up (median, 3-48.8 months [1,11,32,36-39,42,45]) in almost every trial (19-100\% [1,8,11,17,30-34,36-41,43-45]) (Table A.5). Therefore most trials failed to obtain enough data to perform a neurocognitive results analysis after 12 months. The highest compliance rate at 12 months was in Redmond's trial (88.2\%) [41]. The longest follow-up data was from Le Pechoux's trial (33-39\% at 48 months) [39]. As a whole, the compliance in NVALT-11 was the best, ranging from $71.3 \%$ to $100 \%$ at every time point except at 18 months, which was not a pre-planned assessment point according to the protocol $[1,17]$.

\section{Discussion}

Cognitive toxicities of PCI in patients with lung cancer remain a concern and it is not clear which patients are at the highest risk for cognitive decline after PCI. In order to inform physicians and patients, and to personalize selection for PCI with the aim to select only those patients for PCI without a high risk of developing cognitive toxicities, we performed this systematic review. We found that age, PCI dose, PCI frequency (twice-daily instead of once daily), and timing of PCI might be associated with cognitive impairment after PCI in lung cancer patients.

However, not enough validated data has been published until now. The eight included RCTs and eight observational trials did not report detailed assessments of risk factors for neurocognitive decline. Furthermore, none of the trials were judged to be at low risk of bias. The compliance of cognitive assessments dropped rapidly during follow-up, resulting in significant missing data. In addition, assessments for cognitive functioning and definition for cognitive decline also varied between different trials.

Two trials showed that age was a cofactor for cognitive decline after PCI in patients with LD-SCLC (RTOG 0212 [younger or older than 60 years] [45] and Le Pechoux's trial [continuous] [39]. However, RTOG 0214 did not observe significant differences in neurocognitive functioning between the PCI and the observational arm stratified by age (younger or older than 60 years) in stage III NSCLC patients [44]. Nevertheless, it was not reported whether there were significant differences in cognitive function between younger and older patients stratified by PCI. Since the pooled analysis of RTOG 0212 (43.2\% patients) and RTOG 0214 (56.8\% patients) confirmed the association between age ( $\leq 60$ years or $>60$ years) and cognitive decline [36], it is reasonable that for elderly patients, especially SCLC, specific caution should be taken to administer PCI. But it is unknown whether 60 years is the proper cut-off age, as the inclusion criteria regarding age and the actual age range of recruited patients varied between the different trials and in general, a low percentage of older patients was included. Some trials did not set age limitations $[11,44,45]$ while others mandated that recruited patients had to be younger than 70 years $[31,38,39,42]$ or 75 years $[8,43]$. In some trials, age was analyzed as a continuous variable [39]. Furthermore, biological age is not the same as chronological age and it could be that some older patients could be more vulnerable to neurocognitive decline than others.

RTOG 0212 also showed that compared to standard dose, the incidence of chronic neurotoxicity at 12 months was higher in patients treated with a high PCI dose [45]. In contrast, two other trials containing the patients of RTOG 0212 indicated that there were no significant differences in cognitive decline between high and standard dose PCI [36,39]. Notably, in Le Pechoux's trial, only $22 \%$ patients 


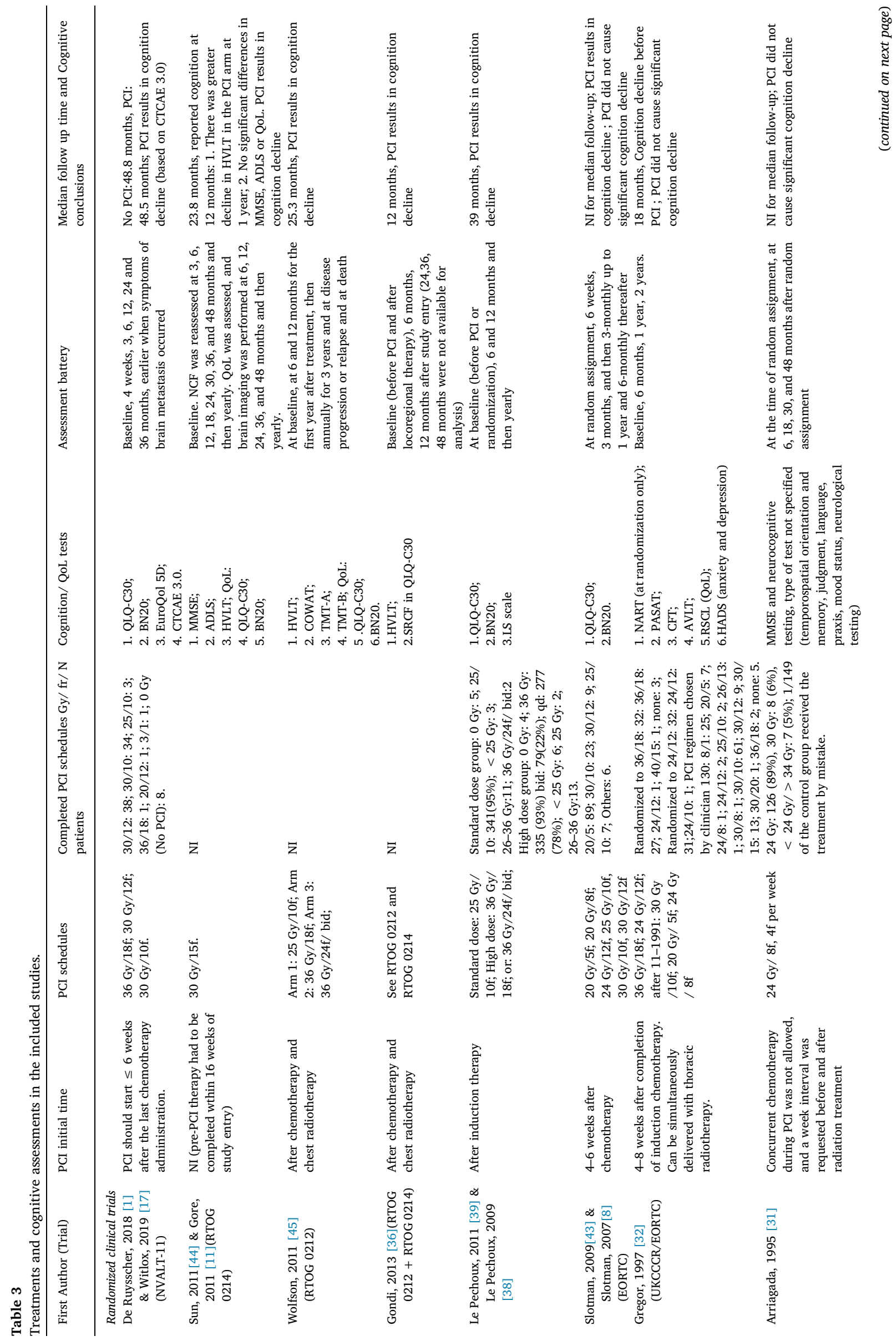




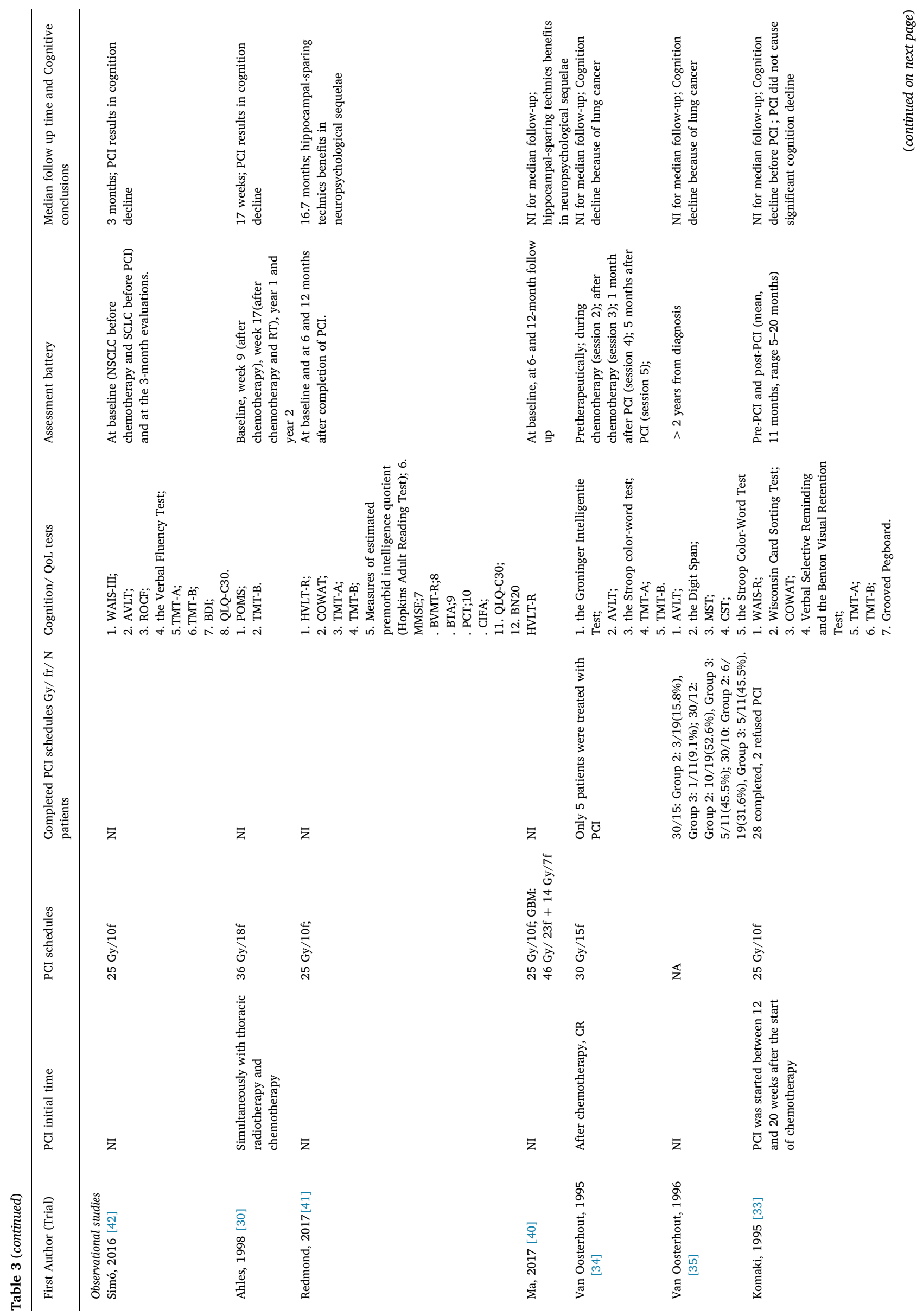




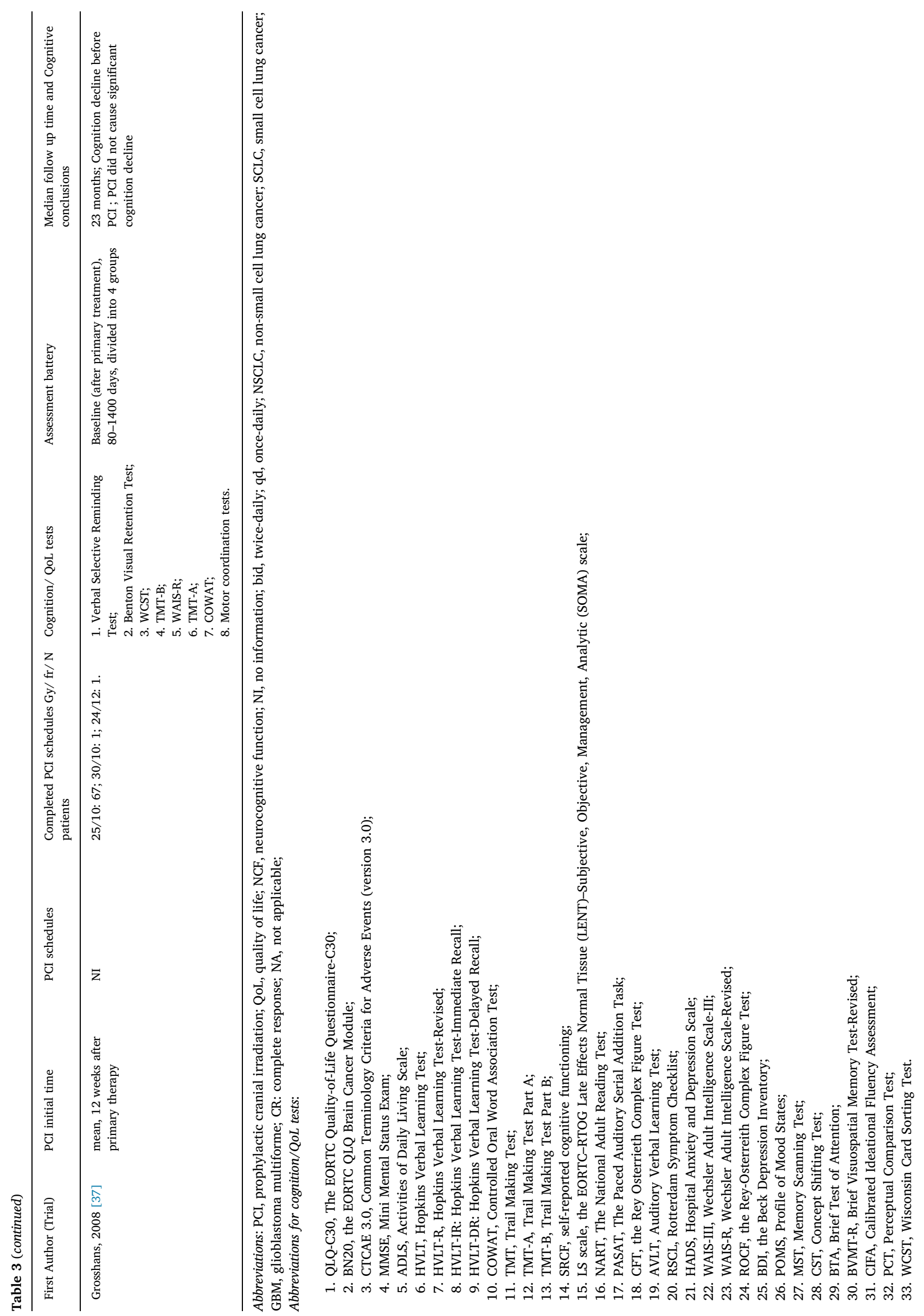




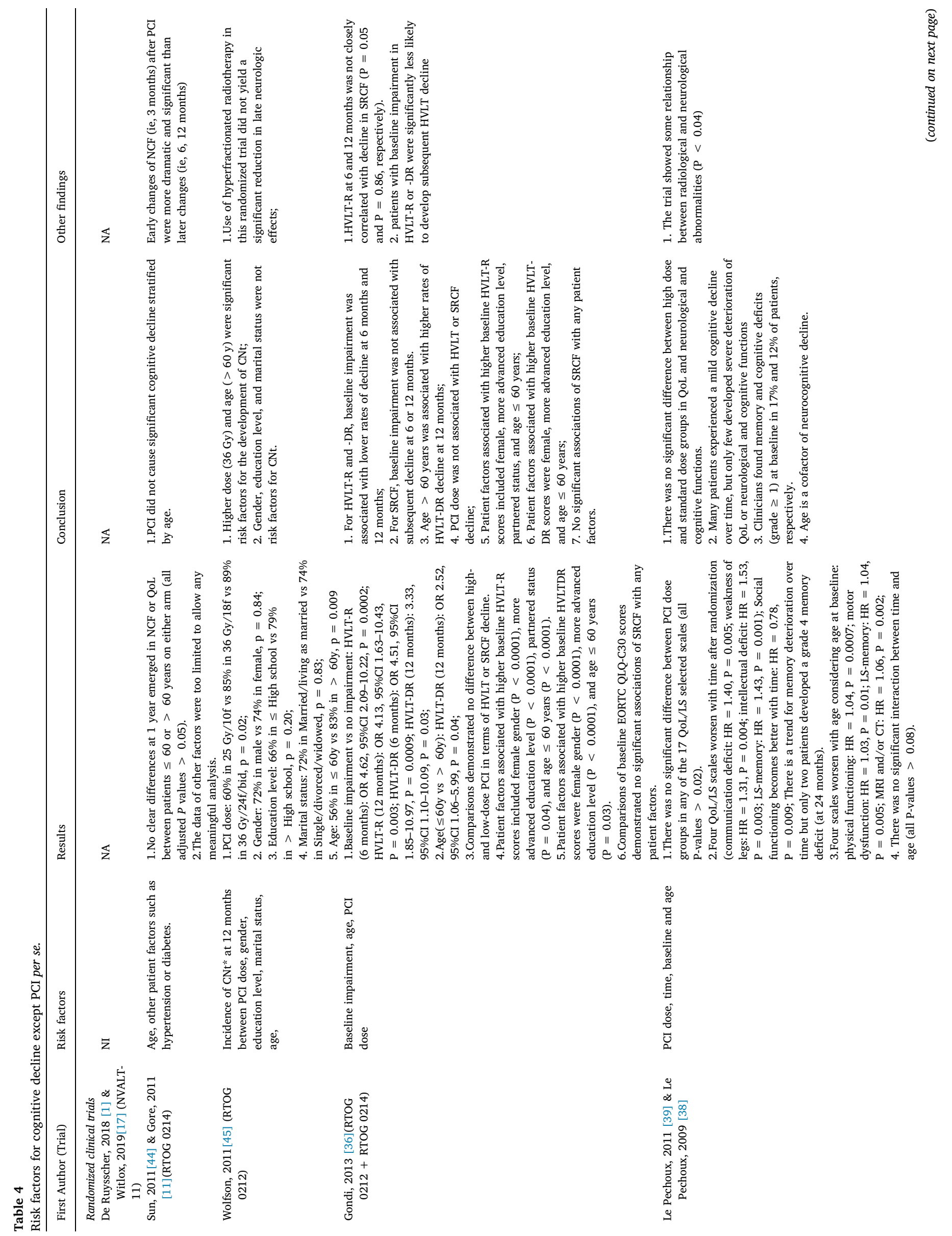




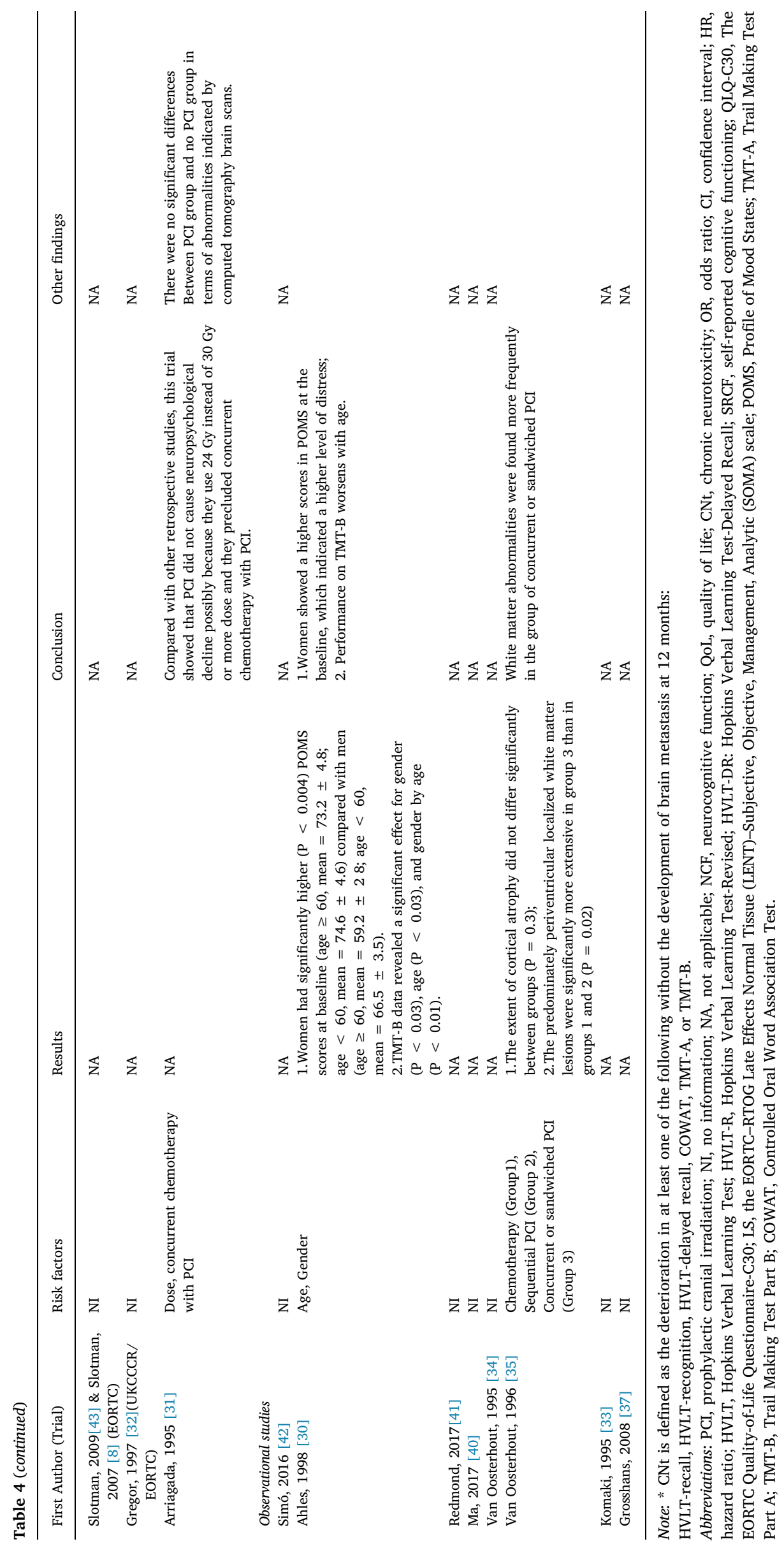


received 36 Gy PCI with twice-daily 24 fractions regimen [38], while in RTOG 0212, 50\% were from this arm [45]. Administration of twicedaily fractions may also have contributed to higher cognitive decline. In addition, PCI concurrent or sandwiched with chemoradiotherapy was found to increase neurotoxicity and hematotoxicity $[18,35,46,47]$, and it was recently shown that it also shortened survival [48]. Therefore, PCI concurrent with chemoradiotherapy should be avoided [49].

It has been suggested that neurocognitive decline is caused especially by irradiation of the hippocampus, and hippocampal-sparing techniques have been evaluated. In patients with BM, the RTOG 0933 trial $(\mathrm{N}=42)$ showed that compared with historical series, HA during whole-brain radiotherapy (WBRT) was associated with preservation of memory and QoL [50]. The phase III NRG Oncology CC001 Trial evaluated the effects of memantine plus WBRT with or without HA in cognition preservation by randomly assigned 518 patients with $\mathrm{BM}$ and showed that compared to WBRT plus memantine, HA-WBRT plus memantine better preserves cognitive function (adjusted HR, 0.74; 95\% CI, 0.58 to $0.95 ; \mathrm{P}=0.02)$ and patient-reported symptoms $(\mathrm{P}<0.05)$ [63]. Another single blinded, randomized phase II trial was $(\mathrm{N}=70,65$ completed treatment) reported in abstract form. Compared with conformal WBRT, patients receiving HA-conformal WBRT had better preservation in late verbal memory, but not in verbal fluency or executive function [51]. Redmond's single-arm observational trial suggested that HA-PCI was associated with less cognitive toxicities at the cost of higher risk of failures in the spared region: two patients developed a metastasis in the under-dosed region [41]. As only 20 of the 125 planned SCLC patients were included, firm conclusions cannot be made. A recent open-label phase II trial showed that for patients with LD SCLC ( $N=44,38$ were evaluable), early HA-PCI does not appear to be better than those receiving sequential PCI without HA in terms of neurocognitive function preservation [52]. Of note, results of this trial were compared with RTOG 0212 data. In this trial, HA-PCI was administered to all patients concomitantly to the 2nd cycle of chemotherapy and thoracic radiotherapy, while in RTOG 0212, patients received PCI after completing of chemotherapy and thoracic radiotherapy [45]. Since PCI concurrent with chemoradiotherapy was found to increase neurotoxicity in several other trials $[18,35,46,47]$, it is questionable whether HAPCI concurrent with chemo(radio)therapy would be beneficial to patients. Recently, the results of a phase III RCT evaluating PCI with or without HA in SCLC have been reported (abstract form) [53]. The primary aim was to evaluate decline in the HVLT-R total recall at 4 months, where a decline of $\geq 5$ out of a possible 36 points was considered a failure. With 168 patients being randomized, it was found that the cognitive decline rate at 4 months was not significantly different for PCI versus HA-PCI (28\% versus $29 \%$ [P $=0.99])$. Moreover, rates at 8 months were similar ( $34 \%$ versus $26 \%$ [P $=0.46]$ ) [53]. The incidence of BM was not significantly different between groups and none of the patients developed BM in the spared zone [53,54]. Results were similar for patients with localized (stage I-III) and metastatic SCLC [55]. In contrast, the Spanish PREMER trial reported contrary results [56]. Among the 118 eligible patients (60 PCI and 58 HA-PCI), there was a significant decline in memory in the PCI versus the HA-PCI group (at 3 months, 21.7 vs $5.1 \%, \mathrm{p}=0.01$; at 6 months, 32.6 vs $7.3 \%$, $\mathrm{p}=0.008$; and at 12 months, 18.5 vs $3.8 \%$; $=0.09$ ). Neurocognitive function was assessed by Free and Cued Selective Reminding Test (FCSRT) which was not used in other HA-PCI trials to the best of our knowledge [56]. Other ongoing RCTs will provide more data on HA-PCI: North America NRG-CC003 (NCT02635009) [57], America (NCT01797159)[80] , Zhejiang, China (NCT02906384) [59], and Taiwan, China (NCT02448992)(NSCLC) [60].

In addition, Ma et al combined Redmond's trial with two glioblastoma multiforme (GBM) trials to evaluate hippocampal radiation dose volume effects and memory decline following cranial irradiation. They observed a dose-response of radiation to the hippocampus with regard to decline in memory: D50\% of the bilateral hippocampi of $22.1 \mathrm{~Gy}$ was associated with $20 \%$ risk of decline [40]. In this combined analysis, 16 out of 30 included patients had SCLC, the others had GBM. As GBM is a completely different disease entity, generally occurring in younger patients, and is treated with different radiation schedules, we think that these results cannot be combined or extrapolated. For example, less co-morbidities could result in less neurocognitive decline, and the higher radiation dose in GBM could result in "collateral damage" of neurons in the region of the hippocampus, responsible for transmitting the information stored earlier by the hippocampus [61]. Therefore, more high quality prospective trials addressing the true dose volume effects of HA-PCI in patients with lung cancer are needed.

Moreover, neuroprotectants during cranial irradiation might also be helpful to prevent or reduce neurotoxicities, although all data till now come from WBRT trials. The randomized phase III RTOG 0614 trial did show positive protection effects of memantine on neurocognitive function in patients treated with WBRT for BM [62]. However, only 149 of the targeted 536 patients were available for analysis, resulting in a statistical power of only $35 \%$. Moreover, we could not identify memantine-related PCI trials. Donepezil combined with vitamin E is another possible neuroprotective agent. However, the double blind, placebo controlled trial set up to test this combination in SCLC patients after completion of all cancer therapy including PCI was closed prematurely due to poor accrual (9 [5 received placebos and 4 received donepezil/ vitamin E] of targeted 104 patients were recruited over 15 months) and conclusions could not be drawn [64]. Again, RCTs are needed to evaluate neuroprotectants in the PCI setting.

Importantly, several studies have demonstrated that cognitive impairments often exists prior to PCI [31-33,37,45]. Some trials showed that patients with lung cancer performed significantly worse than healthy controls in cognitive tests $[34,35,65]$. This indicates that other factors may also have impact on cognition impairment, such as disease related factors including cancer (e.g. paraneoplastic syndromes) $[33,37]$, undiagnosed brain micrometastases [33] and treatment related factors such as chemotherapy, or chemotherapy induced anemia $[31,33,37]$. Lifestyle habits such as smoking and alcohol abuse could influence cognition, as are drugs such as steroids [37]. Comorbidities such as depression [33] and anxiety can cause cognitive impairment [6]. Hypertension, hyperlipidemia, and diabetes that can cause vascular damage and cerebral hypoperfusion could also exacerbate toxicity of cancer treatment and influence results of cognitive functioning tests $[6,37,66,67]$. However, these were not taken into account in any of the PCI trials included in this systematic review.

In summary, PCI per se can result in cognition decline, with an incidence varying from 8 to $89 \%$. Based on the current evidence, to reduce the risk for cognitive decline, PCI concurrently with chemotherapy should be avoided, and PCI should not be given twice-daily or at higher doses. Age might be a risk factor for developing cognitive decline. Other potential risk factors have not been studied thoroughly. HA-PCI and neuro-protective drugs are still under investigation. More highquality clinical trials are warranted to further address this issue, but several challenges in the evaluation of neurocognitive functioning should be addressed.

First, long-term compliance to neurocognitive testing is very challenging. Possible reasons are administrative failure (logistical problems, assessors training) $[32,39,43]$, patients being too ill to complete tests because of disease progression or BM $[31,33,34,37,39,43,68]$, refusal to repeat the tests [39], assessments being voluntary in some protocols [32], and assessments being time-consuming [32]. Possible solutions are minimizing logistical failure by having certified and motivated people doing the tests [31], providing extra funding for education and professional training on cognitive assessments [43], emphasizing necessity and importance of assessments in the protocol, choosing some effective and sensitive but less time-consuming testing instruments, enhancing cooperation from patients by offering reimbursement, performing tests when patients are in clinic for routine oncologic evaluations by the original oncology team [41], and considering to select only good recruiting centers to participate in cognitive trials when studies 
involve patients in the palliative setting [43]. Innovative neurocognitive testing apps [69] or an electronic web-based system could be developed to complete the questionnaires at home. According to RTOG 0828, the web-based strategy appears to be feasible to increase the QoL compliance rate [70].

Second, although neuropsychological testing is very important, testing may be difficult to perform during office practice or at the bedside since it is time-consuming (1-2 h) and demanding for the patient [61]. Cognitive screening tests like Mini Mental Status Exam (MMSE) can provide a quick and easy, although not sensitive, rough measure of a person's cognitive function. Neuropsychological testing is much longer because it comprehensively examines multiple cognitive domains to provide a detailed assessment of the nature and severity of cognitive impairments [71]. Even so, it is probable that "one size does not fit all" exists for cognitive assessments, leading to development of many specialized tests for particular types of impairment [72]. In consist with the International Cognition and Cancer Task Force (ICCTF) published consensus recommendations, the most frequently used instruments in the eligible trials were TMT, HVLT and COWAT [15]. In addition, some factors may also cause potential bias in neuropsychological testing. For example, some medications like antidepressants may ameliorate cognitive deficits, while opioids may worsen cognitive symptoms. Disease progression by itself could also cause neurocognitive decline. Practice may improve performance, so it should be avoided to repeat assessments within 6 months since learning effects may bias short-interval repeated evaluation, except when using parallel versions of tests [61]. Furthermore, some trials assessed the cognitive toxicities of PCI using the QLQ-C30, BN20, or CTCAE, which only contained a domain of cognitive functioning, instead of any cognitive screening tests or neuropsychological testing $[1,8,17,43]$. To complicate matters, patient and physician scored toxicity is not always concordant [1]. Some studies even indicate that proxy sources of QoL data collection like clinician assessments are unreliable and only consider assessments based on patient-reported data for research [73]. However, according to the ICCTF recommendations, objective tests remain the gold standard for measuring cognitive function because self-reported complaints have not been validated as a means to assess cognition, and research shows a stronger association between subjective complaints of cognitive dysfunction and mood and fatigue [15].

Neuroimaging may provide unique objective and important biomarkers of cognitive changes [74]. However, at present, this is experimental $[42,65,75]$. Biomarkers in cerebrospinal fluid are also investigated [76], but not practical for routine use. In contrast, a blood sample is relatively easier to be obtained [77], but no studies have been reported in patients with lung cancer. If validated, blood biomarkers would be very easy to implement to select those who are at risk of neuro-cognitive decline after PCI.

Last, based on our findings, we propose some suggestions for future RCTs. To improve cognitive function research, the following items should be implemented: 1 . The use of an instrument as broad as possible, but still practical neurocognitive testing battery. This is very important to recruit patients, administer interventions and assess outcomes more successfully; 2 . Blinding the assessors to intervention status. This will make the assessment more objective; 3 . Trying to increase the patients' compliance of cognitive assessments, for example with a web-based system. This will lower the trial's risk of bias and make the conclusions more reliable; 4. A systems biology framework incorporating multimodality neuroimaging, genetics and other biomarkers. This will be very informative regarding individual differences in risk and protective factors and disease- and treatment-related mechanisms on cognitive decline [78]; 5. A proper and workable window definition of assessment time point is useful to expand the analyzable data; 6. Briefly specifying in the trial report how the randomization was conducted. This would be helpful for readers to assess randomization bias precisely and interpret the results better.

\section{Conclusion}

In conclusion, our literature search did not yield enough high quality data to define risk factors for developing cognitive decline after PCI. However, it is likely that higher age, PCI dose, twice-daily PCI, and timing of PCI might be associated with cognitive impairment after PCI in lung cancer patients. Protecting cognitive function is an important issue, but there is still a long way to go on cognitive function (or QoL) research in patients with PCI. Future trials should focus on risk factors for both BM development and neurocognitive decline, in order to select those that benefit most from PCI.

\section{Declaration of Competing Interest}

The authors declare that they have no known competing financial interests or personal relationships that could have appeared to influence the work reported in this paper.

\section{Acknowledgements}

This research was supported by the following grant: Scholarship of China Scholarship Council (Grant No. : CSC 201909370087). We sincerely thank Prof. Ben Slotman from Department of Radiation Oncology, VU University Medical Center, Amsterdam, the Netherlands and Prof. Cecile Le Pechoux from Radiation Oncology Department, Institut Gustave Roussy, Villejuif, France for their responses to inquiries about the trials.

\section{Author contributions}

DDR, LH and HZ conceived this study. HZ and LH searched papers in Pubmed. HZ and WVG screening the papers from titles to full texts. $\mathrm{HZ}$ extracted the data and assessed the risk of bias, LH checked the screening, extraction and assessments. HZ analyzed the results, DDR and $\mathrm{HZ}$ supervised the whole process. HZ, LH and DDR draft the manuscript, WVG, WW and DE revised it.

\section{Appendix A. Supplementary material}

Supplementary data to this article can be found online at https:// doi.org/10.1016/j.ctrv.2020.102025.

\section{References}

[1] De Ruysscher D, Dingemans AC, Praag J, Belderbos J, Tissing-Tan C, Herder J, et al. Prophylactic cranial irradiation versus observation in radically treated stage III nonsmall-cell lung cancer: a randomized phase III NVALT-11/DLCRG-02 study. J Clin Oncol 2018;36:2366-77.

[2] Hendriks LE, Schoenmaekers J, Zindler JD, Eekers DB, Hoeben A, De Ruysscher DK, et al. Safety of cranial radiotherapy concurrent with tyrosine kinase inhibitors in non-small cell lung cancer patients: A systematic review. Cancer Treat Rev 2015;41:634-45.

[3] Manapov F, Kasmann L, Roengvoraphoj O, Dantes M, Schmidt-Hegemann NS, Belka C, et al. Prophylactic cranial irradiation in small-cell lung cancer: update on patient selection, efficacy and outcomes. Lung Cancer (Auckl) 2018;9:49-55.

[4] Lowery FJ, Yu D. Brain metastasis: Unique challenges and open opportunities. Biochim Biophys Acta Rev Cancer 2017;1867:49-57.

[5] Andrews DW, Scott CB, Sperduto PW, Flanders AE, Gaspar LE, Schell MC, et al Whole brain radiation therapy with or without stereotactic radiosurgery boost for patients with one to three brain metastases: phase III results of the RTOG 9508 randomised trial. Lancet 2004;363:1665-72.

[6] Pechoux CL, Sun A, Slotman BJ, De Ruysscher D, Belderbos J, Gore EM. Prophylactic cranial irradiation for patients with lung cancer. Lancet Oncol 2016;17:e277-93.

[7] Auperin A, Arriagada R, Pignon JP, Le Pechoux C, Gregor A, Stephens RJ, et al. Prophylactic cranial irradiation for patients with small-cell lung cancer in complete remission. Prophylactic Cranial Irradiation Overview Collaborative Group. N Engl J Med 1999;341:476-84.

[8] Slotman B, Faivre-Finn C, Kramer G, Rankin E, Snee M, Hatton M, et al. Prophylactic cranial irradiation in extensive small-cell lung cancer. N Engl J Med 2007;357:664-72.

[9] Takahashi T, Yamanaka T, Seto T, Harada H, Nokihara H, Saka H, et al. Prophylactic 
cranial irradiation versus observation in patients with extensive-disease small-cel lung cancer: a multicentre, randomised, open-label, phase 3 trial. Lancet Oncol 2017;18:663-71.

[10] Sun A, Hu C, Wong SJ, Gore E, Videtic G, Dutta S, et al. Prophylactic cranial irradiation vs observation in patients with locally advanced non-small cell lung cancer: a long-term update of the NRG oncology/RTOG 0214 Phase 3 randomized clinical trial. JAMA Oncol 2019;5:847-55.

[11] Gore EM, Bae K, Wong SJ, Sun A, Bonner JA, Schild SE, et al. Phase III comparison of prophylactic cranial irradiation versus observation in patients with locally advanced non-small-cell lung cancer: primary analysis of radiation therapy oncology group study RTOG 0214. J Clin Oncol 2011;29:272-8.

[12] Li N, Zeng ZF, Wang SY, Ou W, Ye X, Li J, et al. Randomized phase III trial of prophylactic cranial irradiation versus observation in patients with fully resected stage IIIA-N2 nonsmall-cell lung cancer and high risk of cerebral metastases after adjuvant chemotherapy. Ann Oncol 2015;26:504-9.

[13] National Comprehensive Cancer Network. NCCN guidelines: non-small cell lung cancer, version 3.2020; 2020.

[14] Li J, Bentzen SM, Li J, Renschler M, Mehta MP. Relationship between neurocognitive function and quality of life after whole-brain radiotherapy in patients with brain metastasis. Int J Radiat Oncol Biol Phys 2008;71:64-70.

[15] Wefel JS, Vardy J, Ahles T, Schagen SB. International Cognition and Cancer Task Force recommendations to harmonise studies of cognitive function in patients with cancer. Lancet Oncol 2011;12:703-8.

[16] NCI Common Terminology Criteria for Adverse Events (CTCAE) version 3.0.

[17] Witlox WJA, Ramaekers BLT, Joore MA, Dingemans AC, Praag J, Belderbos J, et al. Health-related quality of life after prophylactic cranial irradiation for stage III nonsmall cell lung cancer patients: Results from the NVALT-11/DLCRG-02 phase III study. Radiother Oncol. 2019;144:65-71.

[18] Crossen JR, Garwood D, Glatstein E, Neuwelt EA. Neurobehavioral sequelae of cranial irradiation in adults: a review of radiation-induced encephalopathy. J Clin Oncol 1994;12:627-42.

[19] Moher D, Liberati A, Tetzlaff J, Altman DG, Group P. Preferred reporting items for systematic reviews and meta-analyses: the PRISMA statement. PLoS Med 2009;6:e1000097.

[20] Al Feghali KA, Ballout RA, Khamis AM, Akl EA, Geara FB. Prophylactic cranial irradiation in patients with non-small-cell lung cancer: a systematic review and meta-analysis of randomized controlled trials. Front Oncol 2018;8.

[21] Gore E, Choy H. Non-small cell lung cancer and central nervous system metastases: should we be using prophylactic cranial irradiation? Semin Radiat Oncol 2004; 14:292-7.

[22] Kotalik J, Yu E, Markman BR, Evans WK. Practice guideline on prophylactic cranial irradiation in small-cell lung cancer. Int J Radiat Oncol Biol Phys 2001;50:309-16.

[23] Meert AP, Paesmans M, Berghmans T, Martin B, Mascaux C, Vallot F, et al. Prophylactic cranial irradiation in small cell lung cancer: a systematic review of the literature with meta-analysis. BMC Cancer 2001;1:5.

[24] Suzuki R, Komaki R. Is prophylactic cranial irradiation indicated for patients with extensive-stage small cell lung cancer with a complete response to first-line treatment? Radiother Oncol 2018;127:339-43.

[25] Precival C, Landy M, Poole C, Mullaney L. The role of prophylactic cranial irradiation for non-small cell lung cancer. Anticancer Res 2018;38:7-14.

[26] Halthore A, Goenka A, Sharma R, Knisely JPS. Prophylactic cranial irradiation for resectable small-cell lung cancer. Clin Lung Cancer 2018;19:115-9.

[27] da Costa Santos CM, de Mattos Pimenta CA, Nobre MR. The PICO strategy for the research question construction and evidence search. Rev Lat Am Enfermagem 2007;15:508-11.

[28] Higgins JPT, Thomas J, Chandler J, Cumpston M, Li T, Page MJ, et al. Cochrane handbook for systematic reviews of interventions version 6.0. Cochrane 2019.

[29] Sterne JAC, Savovic J, Page MJ, Elbers RG, Blencowe NS, Boutron I, et al. RoB 2: a revised tool for assessing risk of bias in randomised trials. BMJ 2019;366:14898.

[30] Ahles TA, Silberfarb PM, Herndon 2nd J, Maurer LH, Kornblith AB, Aisner J, et al. Psychologic and neuropsychologic functioning of patients with limited small-cell lung cancer treated with chemotherapy and radiation therapy with or without warfarin: a study by the Cancer and Leukemia Group B. J Clin Oncol 1998;16:1954-60.

[31] Arriagada R, Le Chevalier T, Borie F, Riviere A, Chomy P, Monnet I, et al. Prophylactic cranial irradiation for patients with small-cell lung cancer in complete remission. J Natl Cancer Inst 1995;87:183-90.

[32] Gregor A, Cull A, Stephens RJ, Kirkpatrick JA, Yarnold JR, Girling DJ, et al. Prophylactic cranial irradiation is indicated following complete response to induction therapy in small cell lung cancer: results of a multicentre randomised trial. United Kingdom Coordinating Committee for Cancer Research (UKCCCR) and the European Organization for Research and Treatment of Cancer (EORTC). Eur J Cancer 1997;33:1752-8.

[33] Komaki R, Meyers CA, Shin DM, Garden AS, Byrne K, Nickens JA, et al. Evaluation of cognitive function in patients with limited small cell lung cancer prior to and shortly following prophylactic cranial irradiation. Int J Radiat Oncol Biol Phys 1995;33:179-82.

[34] van Oosterhout AG, Boon PJ, Houx PJ, ten Velde GP, Twijnstra A. Follow-up of cognitive functioning in patients with small cell lung cancer. Int J Radiat Oncol Biol Phys 1995;31:911-4.

[35] Van Oosterhout AG, Ganzevles PG, Wilmink JT, De Geus BW, Van Vonderen RG, Twijnstra A. Sequelae in long-term survivors of small cell lung cancer. Int J Radiat Oncol Biol Phys 1996;34:1037-44.

[36] Gondi V, Paulus R, Bruner DW, Meyers CA, Gore EM, Wolfson A, et al. Decline in tested and self-reported cognitive functioning after prophylactic cranial irradiation for lung cancer: pooled secondary analysis of Radiation Therapy Oncology Group randomized trials 0212 and 0214. Int J Radiat Oncol Biol Phys 2013;86:656-64.

[37] Grosshans DR, Meyers CA, Allen PK, Davenport SD, Komaki R. Neurocognitive function in patients with small cell lung cancer : effect of prophylactic cranial irradiation. Cancer 2008;112:589-95.

[38] Le Pechoux C, Dunant A, Senan S, Wolfson A, Quoix E, Faivre-Finn C, et al. Standard-dose versus higher-dose prophylactic cranial irradiation (PCI) in patients with limited-stage small-cell lung cancer in complete remission after chemotherapy and thoracic radiotherapy (PCI 99-01, EORTC 22003-08004, RTOG 0212, and IFCT 99-01): a randomised clinical trial. Lancet Oncol 2009;10:467-74.

[39] Le Pechoux C, Laplanche A, Faivre-Finn C, Ciuleanu T, Wanders R, Lerouge D, et al. Clinical neurological outcome and quality of life among patients with limited smallcell cancer treated with two different doses of prophylactic cranial irradiation in the intergroup phase III trial (PCI99-01, EORTC 22003-08004, RTOG 0212 and IFCT 99-01). Ann Oncol 2011;22:1154-63.

[40] Ma TM, Grimm J, McIntyre R, Anderson-Keightly H, Kleinberg LR, Hales RK, et al. A prospective evaluation of hippocampal radiation dose volume effects and memory deficits following cranial irradiation. Radiother Oncol 2017;125:234-40.

[41] Redmond KJ, Hales RK, Anderson-Keightly H, Zhou XC, Kummerlowe M, Sair HI, et al. Prospective Study of Hippocampal-Sparing Prophylactic Cranial Irradiation in Limited-Stage Small Cell Lung Cancer. Int J Radiat Oncol Biol Phys 2017;98:603-11.

[42] Simo M, Vaquero L, Ripolles P, Gurtubay-Antolin A, Jove J, Navarro A, et al. Longitudinal brain changes associated with prophylactic cranial irradiation in lung cancer. J Thorac Oncol 2016;11:475-86.

[43] Slotman BJ, Mauer ME, Bottomley A, Faivre-Finn C, Kramer GW, Rankin EM, et al. Prophylactic cranial irradiation in extensive disease small-cell lung cancer: shortterm health-related quality of life and patient reported symptoms: results of an international Phase III randomized controlled trial by the EORTC Radiation Oncology and Lung Cancer Groups. J Clin Oncol 2009;27:78-84.

[44] Sun A, Bae K, Gore EM, Movsas B, Wong SJ, Meyers CA, et al. Phase III trial of prophylactic cranial irradiation compared with observation in patients with locally advanced non-small-cell lung cancer: neurocognitive and quality-of-life analysis. J Clin Oncol 2011;29:279-86.

[45] Wolfson AH, Bae K, Komaki R, Meyers C, Movsas B, Le Pechoux C, et al. Primary analysis of a phase II randomized trial Radiation Therapy Oncology Group (RTOG) 0212: impact of different total doses and schedules of prophylactic cranial irradiation on chronic neurotoxicity and quality of life for patients with limited-disease small-cell lung cancer. Int J Radiat Oncol Biol Phys 2011;81:77-84.

[46] Ball DL, Matthews JP. Prophylactic Cranial Irradiation: More Questions Than Answers. Semin Radiat Oncol 1995;5:61-8.

[47] Schild SE, Bonner JA, Hillman S, Kozelsky TF, Vigliotti AP, Marks RS, et al. Results of a phase II study of high-dose thoracic radiation therapy with concurrent cisplatin and etoposide in limited-stage small-cell lung cancer (NCCTG 95-20-53). J Clin Oncol 2007;25:3124-9.

[48] Zeng H, Li R, Hu C, Qiu G, Ge H, Yu H, et al. Association of Twice-Daily Radiotherapy With Subsequent Brain Metastases in Adults With Small Cell Lung Cancer. JAMA Netw Open 2019;2:e190103.

[49] National Comprehensive Cancer Network. NCCN guidelines: small cell lung cancer, version $2.2020 ; 2020$.

[50] Gondi V, Pugh SL, Tome WA, Caine C, Corn B, Kanner A, et al. Preservation of memory with conformal avoidance of the hippocampal neural stem-cell compartment during whole-brain radiotherapy for brain metastases (RTOG 0933): a phase II multi-institutional trial. J Clin Oncol 2014;32:3810-6.

[51] Yang WC, Hsu FM, Chen YF, Yang CC, Chen JLY, Kuo SH, et al. A single blind randomized controlled trial of hippocampal avoidance on neurocognitive outcomes after conformal whole brain radiotherapy for brain metastases: an initial analysis. Int J Radiat Oncol Biol Phys 2019;105:S141.

[52] Vees H, Caparrotti F, Eboulet EI, Xyrafas A, Fuhrer A, Meier U, et al. Impact of early prophylactic cranial irradiation with hippocampal avoidance on neurocognitive function in patients with limited disease small-cell lung cancer. A multicenter phase II trial (SAKK 15/12). Int J Radiat Oncol Biol Phys 2020.

[53] Belderbos J, De Ruysscher D, De Jaeger K, Koppe F, Lambrecht M, Lievens Y, et al. OC-0503 Phase III trial of Prophylactic Cranial Irradiation with or without Hippocampus Avoidance in SCLC. Radiother Oncol 2019;133:S259.

[54] Belderbos J, de Ruysscher D, DeJaeger K, Lievens Y, Koppe F, Lambrecht M, et al. Phase III trial of prophylactic cranial irradiation with or without hippocampal avoidance for SMALL-CELL LUNG cancer. Int J Radiat Oncol Biol Phys 2019;105:S35.

[55] van Meerbeeck J, De Ruysscher D, Belderbos J, De Jaeger K, Koppe F, Lambrechts M, et al. Neuro-cognitive (HVLT-R total recall) functioning in localized vs. metastatic small-cell lung cancer with or without hippocampus sparing PCI: Results from a phase III trial. Eur Respir J 2019;54:OA5103.

[56] Rodriguez De Dios N, Murcia M, Counago F, Lopez J, Rico Oses M, Samper Ots PM, et al. Phase III Trial of Prophylactic Cranial Irradiation with or without Hippocampal Avoidance for SMALL-CELL LUNG Cancer. Int J Radiat Oncol Biol Phys 2019;105:S35-6.

[57] Whole-Brain Radiation Therapy With or Without Hippocampal Avoidance in Treating Patients With Limited Stage or Extensive Stage Small Cell Lung. Cancer 2020https://clinicaltrials.gov/ct2/show/NCT02635009.

[59] Memory MRI. changes with hippocampus avoidance prophylactic cranial irradiation (HA-PCI) for Small Cell Lung. Cancer(SCLC) 2020https://clinicaltrials.gov/ ct2/show/NCT02906384.

[60] Hippocampal-Sparing Prophylactic Cranial Irradiation in Pathologically Nodal Positive Non-Small-Cell Lung. Cancer 2020https://clinicaltrials.gov/ct2/show/ NCT02448992.

[61] Zucchella C, Federico A, Martini A, Tinazzi M, Bartolo M, Tamburin S. 
Neuropsychological testing. Pract Neurol 2018;18:227-37.

[62] Brown PD, Pugh S, Laack NN, Wefel JS, Khuntia D, Meyers C, et al, Memantine for the prevention of cognitive dysfunction in patients receiving whole-brain radiotherapy: a randomized, double-blind, placebo-controlled trial. Neuro Oncol 2013;15:1429-37.

[63] Brown PD, Gondi V, Pugh S, Tome WA, Wefel JS, Armstrong TS, et al. Hippocampal avoidance during whole-brain radiotherapy plus memantine for patients with brain metastases: phase III trial NRG oncology CC001. J Clin Oncol 2020::Jco1902767.

[64] Jatoi A, Kahanic SP, Frytak S, Schaefer P, Foote RL, Sloan J, et al. Donepezil and vitamin E for preventing cognitive dysfunction in small cell lung cancer patients: preliminary results and suggestions for future study designs. Support Care Cancer 2005;13:66-9.

[65] Simo M, Root JC, Vaquero L, Ripolles P, Jove J, Ahles T, et al. Cognitive and brain structural changes in a lung cancer population. J Thorac Oncol 2015;10:38-45.

[66] van Meerbeeck JP, Fennell DA, De Ruysscher DKM. Small-cell lung cancer. The Lancet. 2011;378:1741-55.

[67] Kanard A, Frytak S, Jatoi A. Cognitive dysfunction in patients with small-cell lung cancer: incidence, causes, and suggestions on management. J Support Oncol. 2004; 2: 127-32; discussion 33-5, 38-40.

[68] Aaronson NK, Ahmedzai S, Bergman B, Bullinger M, Cull A, Duez NJ, et al. The European organization for research and treatment of cancer QLQ-C30: a quality-oflife instrument for use in international clinical trials in oncology. J Natl Cancer Inst 1993;85:365-76.

[69] Using Artificial Intelligence To Monitor Medication Adherence in Opioid Replacement Therapy; 2019.

[70] Movsas B, Hunt D, Watkins-Bruner D, Lee WR, Tharpe H, Goldstein D, et al. Can electronic web-based technology improve quality of life data collection? Analysis of Radiation Therapy Oncology Group 0828. Pract Radiat Oncol 2014;4:187-91.

[71] Schroeder RW, Martin PK, Walling A. Neuropsychological Evaluations in Adults. Am Fam Phys 2019;99:101-8.
[72] Cullen B, O'Neill B, Evans JJ, Coen RF, Lawlor BA. A review of screening tests for cognitive impairment. J Neurol Neurosurg Psychiatry 2007;78:790-9.

[73] Bottomley A, Efficace F, Thomas R, Vanvoorden V, Ahmedzai SH. Health-related quality of life in non-small-cell lung cancer: methodologic issues in randomized controlled trials. J Clin Oncol 2003;21:2982-92.

[74] Deprez S, Kesler SR, Saykin AJ, Silverman DHS, de Ruiter MB, McDonald BC. International cognition and cancer task force recommendations for neuroimaging methods in the study of cognitive impairment in non-CNS cancer patients. J Natl Cancer Inst 2018;110:223-31.

[75] Simo M, Vaquero L, Ripolles P, Jove J, Fuentes R, Cardenal F, et al. Brain damage following prophylactic cranial irradiation in lung cancer survivors. Brain Imaging Behav 2016;10:283-95.

[76] Kalm M, Abel E, Wasling P, Nyman J, Hietala MA, Bremell D, et al. Neurochemical evidence of potential neurotoxicity after prophylactic cranial irradiation. Int J Radiat Oncol Biol Phys 2014;89:607-14.

[77] van der Willik KD, Koppelmans V, Hauptmann M, Compter A, Ikram MA, Schagen SB. Inflammation markers and cognitive performance in breast cancer survivors 20 years after completion of chemotherapy: a cohort study. Breast Cancer Res 2018;20:135.

[78] Saykin AJ, de Ruiter MB, McDonald BC, Deprez S, Silverman DH. Neuroimaging biomarkers and cognitive function in non-CNS cancer and its treatment: current status and recommendations for future research. Brain Imaging Behav 2013;7:363-73.

[79] Zeng H, De Ruysscher D, Hendriks L, van Geffen W. Risk factors for neurocognitive decline in patients with lung cancer treated with prophylactic cranial irradiation: a systematic review. PROSPERO 2020 CRD42020155776 Available from: https:// www.crd.york.ac.uk/prospero/display_record.php?ID = CRD42020155776.

[80] Hippocampal Prophylactic Cranial Irradiation for Small Cell Lung Cancer; 2020. [Accessed 6 Jan 2020]. 